\title{
Investigation On The Causes Of Distress Affecting Perfomance Of Asphalt Pavement
}

\author{
ZerihunBelayneh Woldesenbet ${ }^{1}$, Mulugeta Regassa Yimam ${ }^{2}$, Mengistu Mena Kuleno ${ }^{3}$ \\ ${ }^{l}$ Resident Engineering, Oromia Health Bureau, Addis Ababa, Ethiopia \\ ${ }^{2}$ Lecturer,Department of Civil Engineering, Bule Hora University, Blue Hora, Ethiopia. \\ ${ }^{3}$ Lecturer, Department of Civil Engineering, Wolaita Sodo University, Wolaita Sodo, Ethiopia
}

\begin{abstract}
Flexible pavements are designed to serve a specified design period without significant failures, but once it was constructed and opened to traffic, after a few years, different types of distresses or damages are occurring. This study focused on the investigation of the causes of the distresses of the study area, which is affecting performance of the pavement. To do the study, a primary data survey performed directly in the field in order to identify, classify, and quantify the extent of defects/distresses. At the same location, samples collected and brought to the laboratory for testing to determine the engineering properties of soils, for both severely distressed and non-distressed sections. It was concluded from the results obtained that the road was constructed with materials with poor engineering properties compared with ERA standard, has lack of routine maintenance strategy and this created condition in which minor distresses expanded to be major distress for the road that highly hinder its performance.
\end{abstract}

Key words: - distress, engineering properties pavement, premature failure, design period, pavement performance maintenance

\section{INTRODUCTION}

\subsection{Background}

Development of a country is highly dependent on the access for public service facilities, and among this facilities access to roads is the most significant one. Road networks are constructed to enhance developmental activities of the country in economic, social, political, and demographic aspect for a specified design period. But for a road network to serve its design period distress is the basic challenge. Distress may occur in a road due to either traffic loading or environmental effects. If distresses in a pavement is not assessed and maintained properly it will affect the road serviceability, safety and riding quality (Magdi M.E Zumrawi, 2015)

The road is composed of $37.7 \mathrm{~km}$ traverses through flat terrain, $40 \mathrm{~km}$ traverses through mountainous terrain and the remaining $52.3 \mathrm{~km}$ traverses though gentle curve and flat terrain. This road is the only road for bale zone to interact with the country. So, it is very important to assess the distresses occurring in this road section to provide proper management to make the road serve the community properly. This paper is designed to classify and measure distresses in the road section, study causes of failure, study impact of the road failure on the community using the road and develop remedial measure (ERA RSDSP II, 2003).

\subsection{Statement of the Problem}

The road from Dodola to Bale Goba is one of Ethiopian roads that huge number of community is using for access as the only option. But this road section has been experiencing many distresses which if not assessed and maintained properly result in a complete failure of the road. To conserve the 
serviceability of the road it is very important to make a field survey to classify the different distress types and quantify their severity, to study the actual cause of failure for distress types existing on the road so that it will be simple to select remedial measure may it be maintenance, rehabilitation or other measure.

\subsection{Objectives of the Study}

\subsubsection{General objective}

The main objective of the paper is to investigate the causes ofdistresses affecting performance of the pavement along the road from Dodola to Bale Goba road.

\subsubsection{Specific objectives of the study}

$>$ To Assess, measure the extent and classify according to the severity of distresses at the affected road sections.

$>$ To determine the engineering properties of the severely distressed and non-distressed sections of the pavement materials in eachlayer and compare with the ERA Standard Specifications as a cause of distress.

$>$ To assess the impact of pavement distresses on the road users.

\section{REVIEW OF RELATED LITERATURES}

\subsection{Introduction}

One of the essential features of road transport infrastructure is pavement. Pavements are designed to serve at least a specified design period before failure. Thus, road pavements need to be sufficientlymaintained in order to provide service with acceptable riding quality for its design life.Generally according to Yang H. Huang (2004) There are three major types of pavements: flexible or asphalt pavements, rigid or concrete pavements, and composite pavements.

Table 1. Pavement distress quantification (ERA 2013)

\begin{tabular}{|c|c|c|c|}
\hline \multirow[t]{2}{*}{ Damage } & \multicolumn{3}{|l|}{ Pavement failure Severity } \\
\hline & Level-1 & Level-2 & Level-3 \\
\hline $\begin{array}{l}\text { Deformation } \\
\text { /Rutting }\end{array}$ & $\begin{array}{l}\text { Perception to User but } \\
\text { small Depth }<2 \mathrm{~cm}\end{array}$ & $\begin{array}{l}\text { Severe deformations, } \\
\text { localized subsidence } \\
\text { or rutting } 2 \leq \mathrm{f} \leq 4 \mathrm{~cm}\end{array}$ & $\begin{array}{l}\text { Deformation severely } \\
\text { affecting safety or travel time } \\
f>4 \mathrm{~cm}\end{array}$ \\
\hline Crack & $\begin{array}{lll}\text { Hairline } & \text { cracks } & \text { in } \\
\text { wheel } & \text { path } & \text { or } \\
\text { centerline } & & \end{array}$ & $\begin{array}{l}\text { Open or branching } \\
\text { cracks }\end{array}$ & $\begin{array}{l}\text { Markedly branched or wide } \\
\text { open cracks }\end{array}$ \\
\hline Crazing & $\begin{array}{l}\text { Fine crazing with no } \\
\text { loss of materials large } \\
\text { mesh }(>50 \mathrm{~cm})\end{array}$ & $\begin{array}{l}\text { Tighter crazing } \\
(<50 \mathrm{~cm})\end{array}$ & $\begin{array}{l}\text { Very open crazing forming } \\
\text { blocks }(<20 \mathrm{~cm}) \text { accompanied } \\
\text { by loss of materials }\end{array}$ \\
\hline $\begin{array}{l}\text { Patch and } \\
\text { Repair }\end{array}$ & $\begin{array}{l}\text { Rebuilding of } \\
\text { pavement }\end{array}$ & Surface work related & Surface work related \\
\hline Pothole & $\begin{array}{l}\text { Number less than } 5 \\
\text { Diameter not more } \\
\text { than } 30 \mathrm{~cm}\end{array}$ & $\begin{array}{l}\text { Number } 5 \text { to } 10 \\
\text { Diameter } 30 \mathrm{~cm} \text { to } \\
100 \mathrm{~cm} \text { (per } 100 \mathrm{~m} \text { of } \\
\text { pavement) }\end{array}$ & $\begin{array}{l}\text { Number }>10 \\
\text { Diameter } 30 \mathrm{~cm} \text { to } 100 \mathrm{~cm} \\
\text { (per } 100 \mathrm{~m} \text { of pavement) }\end{array}$ \\
\hline Raveling & Localized & Continuous & $\begin{array}{l}\text { Continuous and road base } \\
\text { visible }\end{array}$ \\
\hline
\end{tabular}




\subsection{Pavement maintenance strategies}

According to ERA (2013), all roads deteriorate with time as a result of traffic and environmental effects. The deterioration may be relatively easy to correct or may require major works, depending on the causes and extent of deterioration. The works processes for keeping roads in good condition are often subdivided into the following categories:

(i). Routine maintenance - maintenance that needs to be done at relatively short intervals such as cutting grass and cleaning drainage ditches.

(ii). Emergency maintenance - maintenance that has to be done immediately as a result of an unexpected problem e.g., clearing a rock fall.

(iii). Periodic maintenance - maintenance that needs to be done at longer intervals of, say, 5-10 years e.g., surface dressing. Usually, this category excludes structural strengthening.

(iv). Rehabilitation - this term is commonly used when structural strengthening is required and includes overlaying.

(v). Reconstruction - this usually means that at least one layer of the pavement needs to be reprocessed.

(vi). Upgrading - this usually means that strengthening and some realignments are required. The main distinguishing feature of the categories of maintenance is that the costs increase steadily from 'routine maintenance' up to 'upgrading'.

As a result, the responsibility for each operation may differ. However, it can be seen that there is considerable overlap between the categories and in the process of keeping the road in good condition it is not helpful to be concerned about precise definitions. Roads can deteriorate (and fail) in many different ways and the repairs that they require depend on the causes of deterioration. This is the guiding principle of pavement rehabilitation namely that 'the repairs are determined by the cause or causes of the deterioration and the degree to which the deterioration has progressed'. Identifying these causes is therefore of paramount importance. Applying the wrong remedial treatment could be a waste of time and money.

\section{MATERIAL AND RESEARCH METHODOLOGY}

\subsection{Description of the study area}

The road is composed of $37.7 \mathrm{~km}$ which traverses through flat terrain from Dodola junction to AdabaKela, 40km traverses through mountainous terrain from AdabaKela to Soba kebele and the remaining $52.3 \mathrm{~km}$ traverses though gentle curve and flat terrain from Soba kebele to Bale Goba. The road stretch lies in elevation ranging from $1890 \mathrm{~m}$ to $3500 \mathrm{~m}$ above sea level which can be categorized based on the ERA Site investigation manual (2013) as Weina-dega to Dega climate condition. This implies it is with moderate to high rainfall every year.

\subsection{Research Design}

This research was designed based on purposive sample selection technique in which the road stretch was classified in different sections with similar distress distribution and samples from each sections were selected purposively, causes of distress were investigated by taking sample based on the sample size specified in the test manual in use to conduct laboratory tests using ASTM \& AASHTO 


\subsection{Population}

For the purpose of this research the population is the road from Dodola to Bale Goba, and the distresses and vehicles on the road. These populations were used to obtain all necessary data to conduct the required operations to meet the research objectives.

\subsection{Study Variables}

These include engineering properties of pavement materials, distress, distress impacts on the road users, and the pavement surface conditions.

\subsection{Software and instruments}

The following instruments and software were used for this study: Meter tape, plastic bags, manual hand auger equipment, laboratory equipment's, and field test instrument, Digital Camera for documentation, MS word and Excel to analyze laboratory data and display research data were used in this study.

\subsection{Data Collection Process}

Since data collection is conducted by directly visiting the site and includes destructive data collection, legal permission was received from Ethiopian Roads Authority Shashemene district which allows the researcher to collect all necessary data from the site.

Data needed to conduct this research can broadly be classified as primary data (data that can be obtained from field survey) and secondary data. More specifically the data required for this research work were classified into three basic categories as

- Pavement condition survey data in which the researcher has collected data required to classify measure and rate severity of the pavement distresses encountered on the road by visually visiting the road section.

- Construction materials quality investigation in which the researcher has collected material samples from onsite and conduct basic laboratory tests that can help decide what the quality of construction materials is as a cause of pavement distress.

- Vehicle Speedreduction due to pavement distress investigations to examine to what extent distresses on the pavement can affect the community using the road.

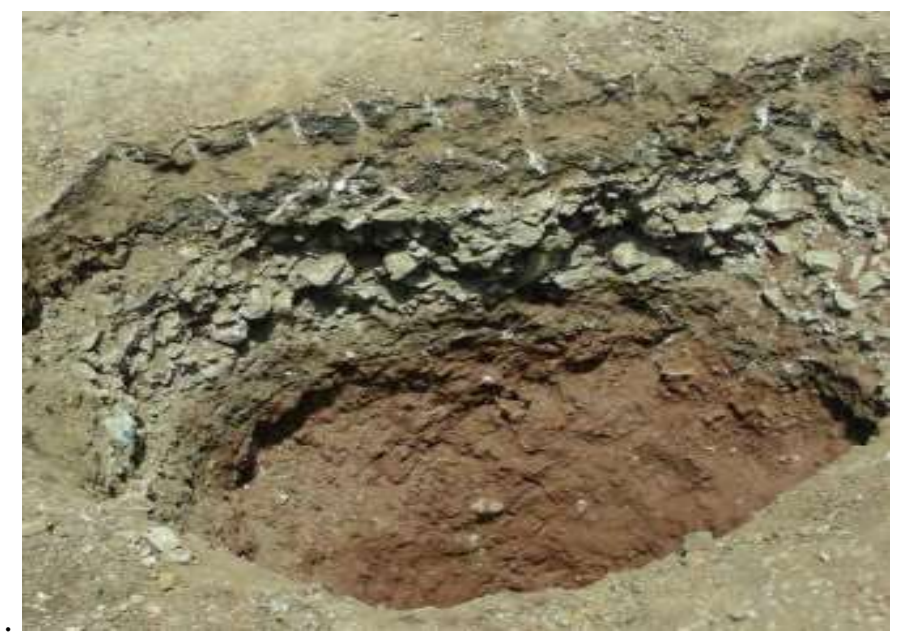

Figure 1. Sample test pit for collecting material sample for laboratory tests. 


\section{RESULT AND DISCUSION}

\subsection{Road Alignment Features}

An average width of $9.3 \mathrm{~m}$ was recorded for the entire study route.Section 1, which starts from the Dodola-Assela-Shashemene junction and stretch for about $45 \mathrm{~km}$ to Adabakela. This section has four town sections namely Dodola, Herero and Adaba towns where the road has provided with town section widening. The elevation in this section ranges from $2350 \mathrm{~m}$ to $2800 \mathrm{~m}$ above sea level. This section is of nearly similar flat terrain condition and the soil condition comprises dark brown clay and black cotton type.

Table 2. Average width per section and other road features

\begin{tabular}{|l|l|l|l|}
\hline Section No: & Section Name & Average Width, m & Shoulder \\
\hline 1 & Dodola Junction-AdabaKela & 8.5 & Yes \\
\hline 2 & AdabaKela - Soba Kebele & 10.2 & Yes \\
\hline 3 & Soba Kebele - Bale Goba & 9.2 & Yes \\
\hline
\end{tabular}

Table 3. Pavement layers thickness measurement

\begin{tabular}{|l|l|l|l|}
\hline \multirow{2}{*}{ Station } & \multicolumn{3}{|l|}{ Pavement layers and their thickness, $\mathrm{cm}$} \\
\cline { 2 - 4 } & Asphalt, cm & Base coarse, cm & Sub-base, cm \\
\hline $2+560$ & 4.33 & 14.2 & 25.1 \\
\hline $6+300$ & 3.75 & 15.05 & 26.3 \\
\hline $50+100$ & 3.80 & 13.12 & 26.7 \\
\hline $69+800$ & 3.64 & 14.0 & 25.88 \\
\hline $80+00$ & 3.98 & 13.8 & 25.0 \\
\hline $104+600$ & 3.76 & 13.86 & 25.4 \\
\hline
\end{tabular}

\subsection{Pavement Condition Survey Result}

The actual status of pavement condition can be understood by making visual condition survey to measure the extent, rate the severity, classify the type of distress occurred in the pavement and collect sample material used for the construction in order to conduct laboratory tests to investigate causes of pavement distress. The pavement condition survey was conducted in two phases: -

\subsubsection{Distress Distribution Identification: -}

The first phase was to make rough visual survey to identify the general road condition and determine sections of the road with nearly similar distress distribution condition. This was made to identify road section which is with more distress and needs detailed investigation on the causes of distress. According to the result obtained from survey the road from Dodola junction to Bale Goba can be classified based on its surface condition and terrain type to three main sections. 
Table 4. Pavement distress distribution along the case study road

\begin{tabular}{|l|l|l|l|}
\hline Name of road section & Chainage & to & Distress condition \\
\hline & From & 45 & \\
\hline 1 & 0 & 74 & Intermediate distress \\
\hline 2 & 45 & 130 & Severely distressed \\
\hline 3 & 74 & Minor distress \\
\hline
\end{tabular}

Pavement distressesidentified and recorded as distresses clearly observed during second phase detail visual pavement condition survey are: - Alligator Cracks, Potholes/Patches, shoving, Raveling and Edge failure.

\subsubsection{Distress Extent Measurement and Severity Classification: -}

The detail pavement condition survey was conducted for the entire road, and summarized at every $5 \mathrm{~km}$ interval for failure types of alligator cracking, potholes and patching, shoving, edge failure and raveling identified during identification phase. As the distress survey result implies the road has experienced alligator crack more than all types of distresses, which can be presented in percent as about $19.74 \%$ of the total pavement surface area for section one, about $35.37 \%$ of the total pavement surface of section two and $9.52 \%$ of the total pavement surface of section three has experienced alligator crack. Among these alligator crack in section three is maximum. More specifically the extent to which the pavement has experienced distress relative to the total pavement surface is presented in table 5 as: -

Table 1. Extent of distress area relative to the total area of pavement surface in each section.

\begin{tabular}{|c|c|c|}
\hline distress types & area, $\%$ & Total \\
\hline \multicolumn{3}{|c|}{ section no: 1} \\
\hline Alligator crack & $19.74 \%$ & \multirow{5}{*}{$22.40 \%$} \\
\hline pothole and patch & $1.96 \%$ & \\
\hline edge failure & $0.31 \%$ & \\
\hline Shoving & $0.06 \%$ & \\
\hline Raveling & $0.32 \%$ & \\
\hline \multicolumn{3}{|l|}{ section no: 2} \\
\hline Alligator crack & $35.37 \%$ & \multirow{5}{*}{$42.06 \%$} \\
\hline pothole and patch & $4.53 \%$ & \\
\hline edge failure & $0.81 \%$ & \\
\hline Shoving & $0.13 \%$ & \\
\hline Raveling & $1.23 \%$ & \\
\hline \multicolumn{3}{|l|}{ section no: 3} \\
\hline Alligator crack & $9.52 \%$ & \multirow{5}{*}{$10.78 \%$} \\
\hline pothole and patch & $1.15 \%$ & \\
\hline edge failure & $0.03 \%$ & \\
\hline Shoving & $0.05 \%$ & \\
\hline raveling & $0.02 \%$ & \\
\hline
\end{tabular}

Alligator crack: - Alligator cracking may be considered a combination of fatigue and block cracking. (FHWA 2006). The general alligator crack distribution observed throughout the road stretch under study can be presented as shown in the figure 2 . 


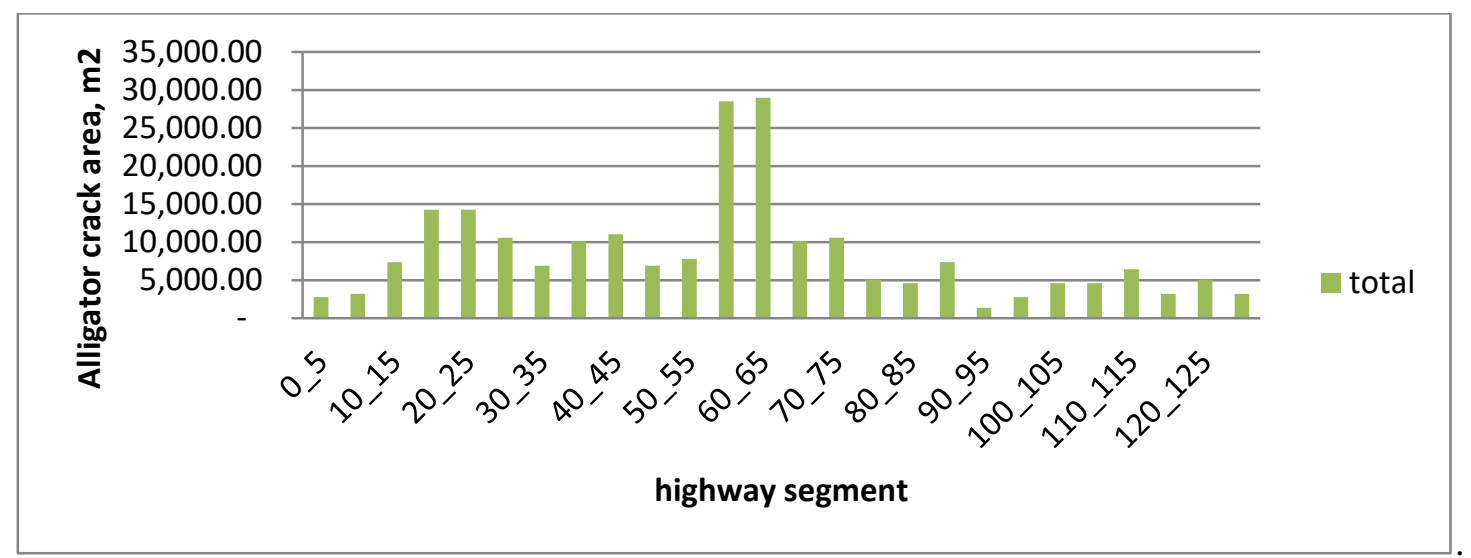

Figure 1. Alligator crack distribution in the total road section.

Figure 3showed alligator crack severity distribution. It can be understood that highly severe alligator crack was observed in section two of the road section. Section one has experienced relatively fewer highly severe alligator crack compared to section two, and section three has least amount of highly severe alligator crack.

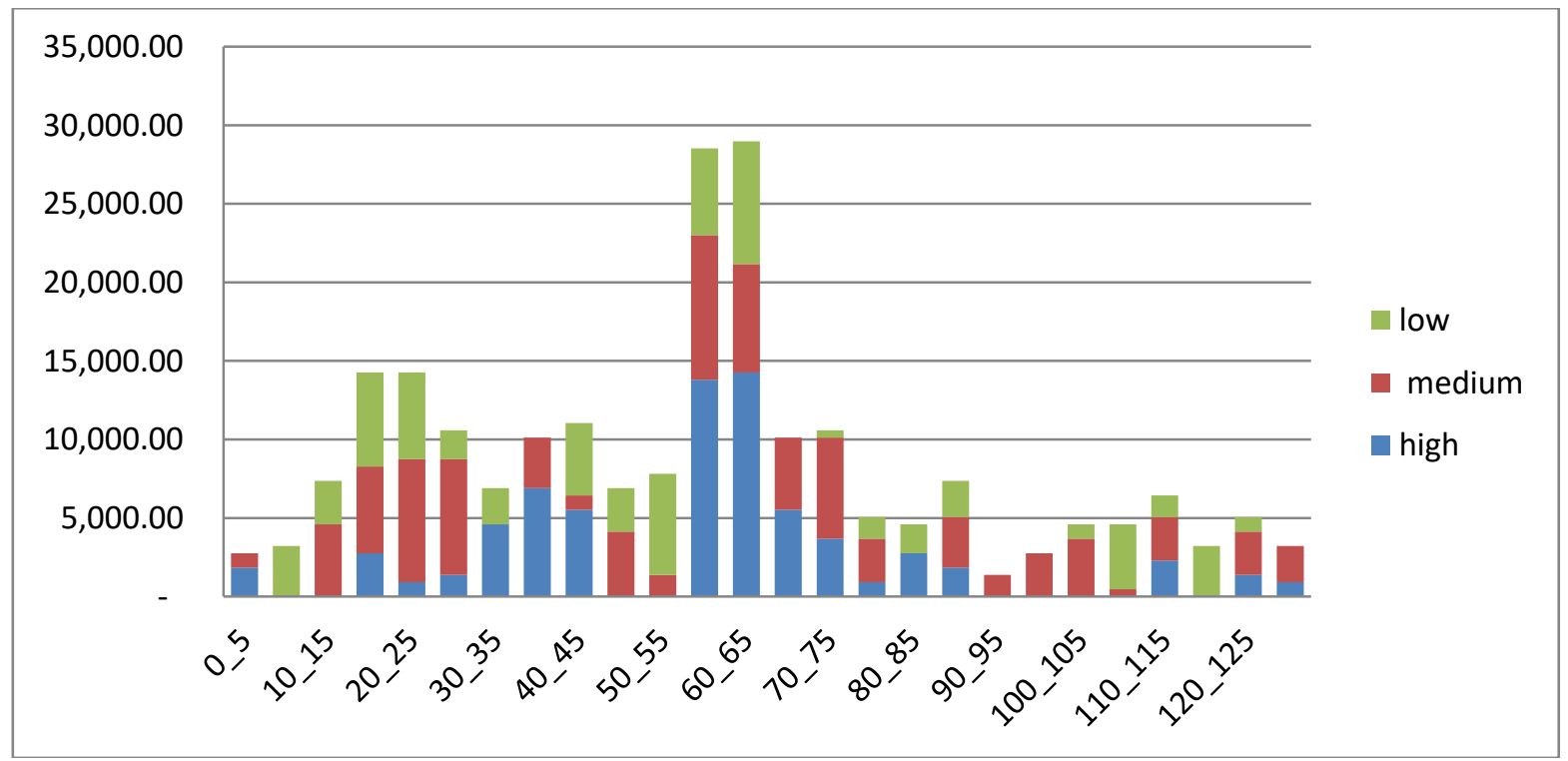

Figure 2. Alligator crack severity distribution

Thedata plotted in table 5 showed alligator crack distribution per $5 \mathrm{~km}$. it is clearly shown that section one of the road section encountered $1,788.89 \mathrm{~m} 2$ alligator crack per kilometer, section two encountered $4,424.76 \mathrm{~m} 2 / \mathrm{km}$, and section three encountered $754.69 \mathrm{~m} 2 / \mathrm{km}$. These data implied that high intensity of alligator crack per km was observed in section two.

Table 5. Comparison of alligator crack distribution per $\mathrm{km}$

\begin{tabular}{|l|l|l|}
\hline highway segment & $\mathrm{Km}$ & $\mathrm{m} 2 / \mathrm{km}$ \\
\hline section 1 & $0-45$ & $1,788.89$ \\
\hline section 2 & $45-74$ & $4,424.76$ \\
\hline section 3 & $74-130$ & 754.69 \\
\hline
\end{tabular}

Pothole and patch: - 
Pothole and patch area distribution in the road is presented in the figure 4.5. The figure pointed out that high intensity of potholes and patch area was observed in section two, more specifically from $\mathrm{km} 55$ to $\mathrm{km}$ 65. Section one also has relatively high intensity of pothole and patch.

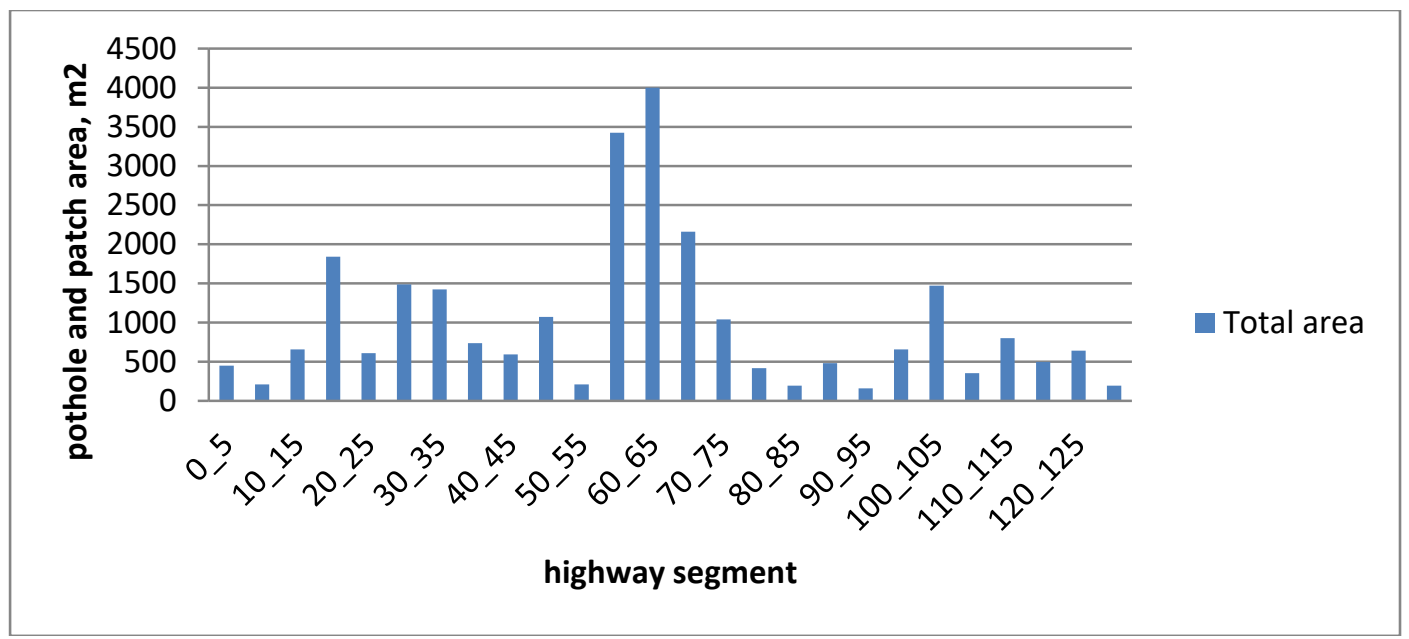

Figure 3. Pothole and patch area distribution in the road

\subsubsection{Pavement condition rating}

Pavement condition index is a good indicator for understanding the general status of a pavement road. For this research purpose ASTM D6433 elaborated in the literature review were used to compute the pavement condition index. The computation result and the range classification summary for PCI are presented in table 4.8. The result show that the three subsections of the road under study was in different pavement condition.

Table 6. Pavement condition rating (per ASTM Standard)

\begin{tabular}{|c|c|c|}
\hline \multirow{2}{*}{ road segment } & \multicolumn{2}{|c|}{ PCI summary } \\
\hline & PCI, \% & Rating \\
\hline 1 & 62.24 & Good \\
\hline 2 & 20.88 & very poor \\
\hline 3 & 84.46 & very good \\
\hline
\end{tabular}

\subsection{Investigation of causes of distress}

\subsubsection{Laboratory tests}

Construction material quality is one of the basic factors for good performance of a pavement road. So, it is very important to investigate materials quality in use for construction of the road. Different materials have different approach to evaluate their property.

For this study different tests were selected to be performed to understand materials property. For soil materials used for subgrade and sub-base material property tests selected were grain size distribution test, Atterberg limit test, proctor compaction test and California bearing ratio test. To conduct these tests sample was collected from six test pits, two from each sub section, one from distressed area and one from non-distressed area in which purposive sampling approach was applied. 
For asphalt materials bitumen extraction test was conducted to understand the bitumen content and aggregate gradation used for asphalt mix. To conduct this test one sample core was collected from each sub section. Aggregate gradation test was also conducted for base coarse layer for each six test pits parallel with soil tests.

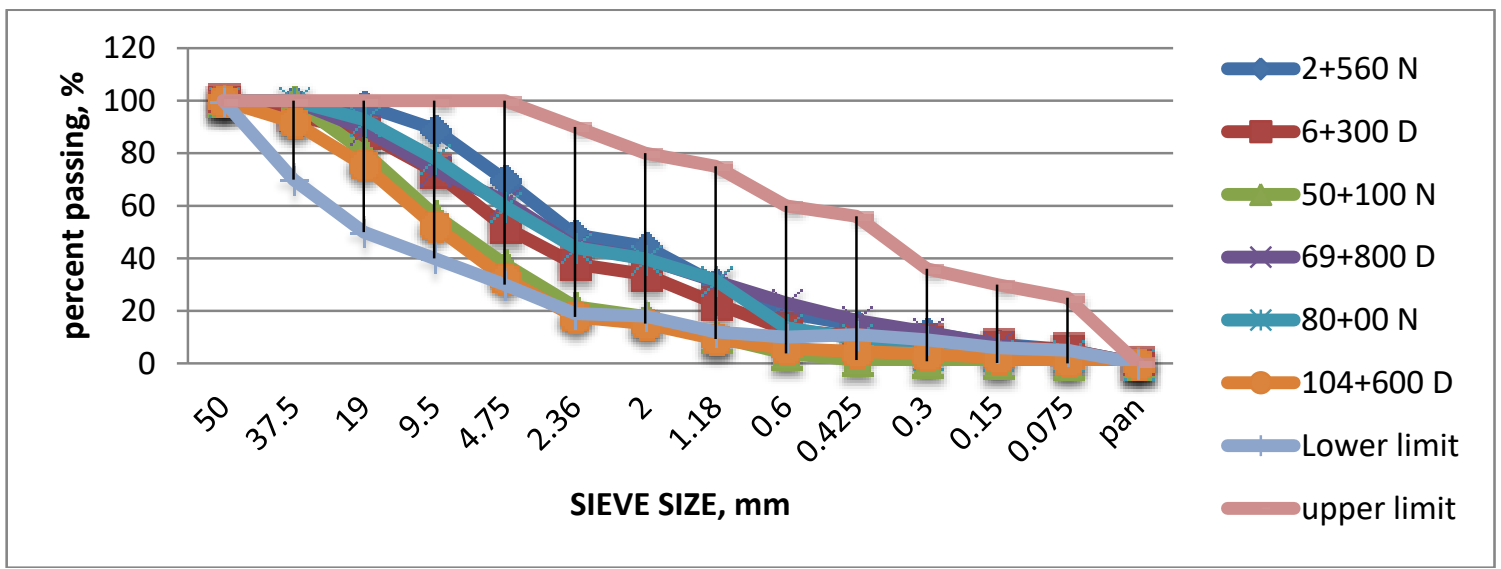

Figure 6Sub-base grain size distribution relative to ERA specification grain size distribution requirement

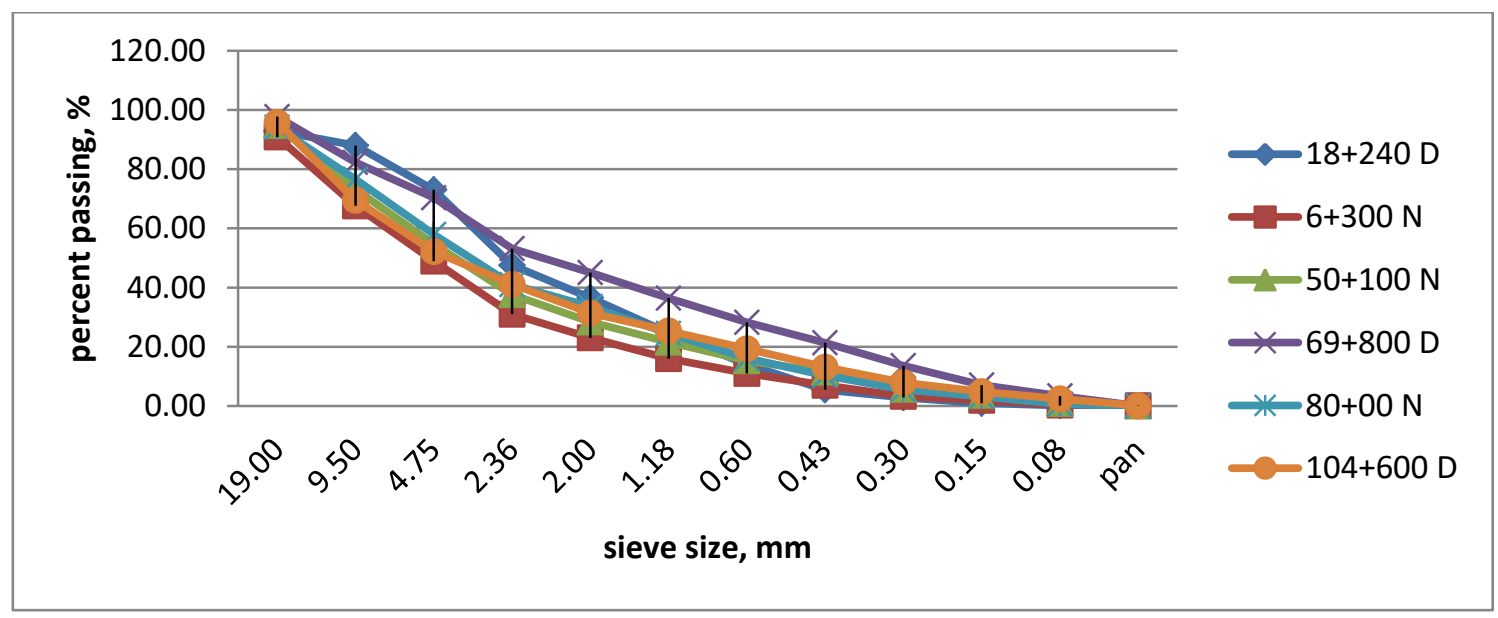

Figure 7. Subgrade grain size distribution\

\subsubsection{Subgrade laboratory test result summary}

Table 7. Subgrade CBR, PI, OMC and MDD test result summary

\begin{tabular}{|l|l|l|l|l|l|}
\hline S.N, & Station, $\mathrm{km}$ & CBR, \% & PI, \% & OMC, \% & MDD, g/cm3 \\
\hline 1 & $6+300$ & 3.93 & 19.55 & 25.25 & 1.158 \\
\hline 2 & $18+240$ & 3.28 & 29.04 & 32.5 & 1.065 \\
\hline 3 & $50+100$ & 4.61 & 21.87 & 28.45 & 1.045 \\
\hline 4 & $69+800$ & 3.36 & 34.59 & 29.39 & 1.015 \\
\hline 5 & $80+00$ & 3.20 & 16.54 & 20 & 1.297 \\
\hline 6 & $104+600$ & 3.33 & 32.93 & 25 & 1.24 \\
\hline
\end{tabular}


Table 8. Sub-base CBR, PI, OMC and MDD test result summary

\begin{tabular}{|l|l|l|l|l|l|}
\hline S.N, & Station, $\mathrm{km}$ & CBR, \% & PI, \% & OMC, \% & MDD, g/cm3 \\
\hline 1 & $6+300$ & 20.26 & 13.96 & 24.5 & 1.395 \\
\hline 2 & $18+240$ & 16.89 & 15.2 & 19.8 & 1.188 \\
\hline 3 & $50+100$ & 21.81 & 12.9 & 15 & 1.278 \\
\hline 4 & $69+800$ & 18.28 & 16.41 & 20.39 & 1.248 \\
\hline 5 & $80+00$ & 26.12 & 11.26 & 14.25 & 1.31 \\
\hline 6 & $104+600$ & 19.97 & 12.99 & 16.75 & 1.284 \\
\hline
\end{tabular}

Table 9. Base coarse gradation test result summary

\begin{tabular}{|c|c|c|c|c|c|c|c|c|}
\hline \multirow{2}{*}{ sieve size, mm } & \multicolumn{9}{|c|}{ percent pass } & ERA spec \\
\cline { 2 - 10 } & $18+240 \mathrm{D}$ & $6+300 \mathrm{~N}$ & $50+100 \mathrm{~N}$ & $69+800 \mathrm{D}$ & $80+00 \mathrm{~N}$ & $104+600 \mathrm{D}$ & lower limit & upper limit \\
\hline 37.5 & 100 & 100 & 100 & 100 & 100 & 100 & 95 & 100 \\
\hline 20 & 75 & 65 & 79 & 77 & 68 & 65 & 60 & 80 \\
\hline 10 & 52 & 50 & 59 & 48 & 56 & 44 & 40 & 60 \\
\hline 5.00 & 37 & 32 & 38 & 28 & 36 & 26 & 25 & 40 \\
\hline 2.36 & 28 & 25 & 23 & 18 & 28 & 19 & 15 & 30 \\
\hline 0.425 & 14 & 12 & 18 & 8 & 16 & 11 & 7 & 19 \\
\hline 0.075 & 9 & 6 & 13 & 4 & 7 & 8 & 5 & 12 \\
\hline PAN & & & & & & & & \\
\hline
\end{tabular}

Table 10. Bitumen content extraction test result and asphalt aggregate sieve analysis result

\begin{tabular}{|l|l|l|l|}
\hline S.No & \multicolumn{1}{|c|}{ Station } & Bitumen content, \% & \multicolumn{1}{c|}{$\begin{array}{c}\text { Aggregate gradation relative to ERA 2013 } \\
\text { Specification }\end{array}$} \\
\hline 1 & $6+300$ & 4.17 & Finer \\
\hline 2 & $18+240$ & 3.77 & Coarser \\
\hline 3 & $50+100$ & 4.12 & Coarser \\
\hline 4 & $69+800$ & 3.97 & Coarser \\
\hline 5 & $80+000$ & 4.11 & Finer \\
\hline 6 & $104+600$ & 3.95 & Coarser \\
\hline
\end{tabular}

Table 11. Forecasted traffic load data

\begin{tabular}{|l|c|c|c|c|}
\hline \multicolumn{1}{|c|}{ Vehicle } & $\begin{array}{c}\text { AADTo at } \\
2010\end{array}$ & $\begin{array}{c}\text { Cumulative number } \\
\text { of vehicles }\end{array}$ & $\begin{array}{c}\text { Equivalency factor from } \\
\text { ERA 2013 }\end{array}$ & $\begin{array}{l}\text { Total ESA } \\
\left(10^{\wedge} 7\right)\end{array}$ \\
\hline Passengers' car & 141 & $1,701,739$ & 0 & 0 \\
\hline Small bus & 134 & $1,617,256$ & 0.15 & 0.024 \\
\hline Bus & 91 & $1,098,286$ & 1 & 0.069 \\
\hline Small truck & 82 & 989,664 & 2.5 & 0.220 \\
\hline Medium truck & 73 & 881,042 & 5 & 0.272 \\
\hline Large truck & 45 & 543,108 & 7.5 & 0.371 \\
\hline Trucks \& trailers & 41 & 494,832 & \multicolumn{3}{|c|}{ Total ESAs } & 1.066 \\
\hline
\end{tabular}




\section{CONCLUSION}

The overall analysis in the study is based on the road condition at the time of testing. In the analysis, pavement failure was assumed to be associated with excess traffic loading, poor workmanship, expansive subgrade and use of poor-quality materials.The road from Dodola-Bale Gobahas been in very rare maintenance and no study was conducted to figure out causes of distress in the road. So, Detail field and laboratory investigation which consists of, visual condition survey,test pitting and material sampling and testing have been conducted in order to investigate the causes of failure.Visual pavement condition survey indicates that distress distribution throughout the road was not uniform. There are distress free sections where as there are highly distressed sections especially from $55 \mathrm{~km}$ to $74 \mathrm{~km}$. this implies that causes of failure are not uniform throughout the stretch.In connection with the above conclusion the visual pavement condition survey revealed that improper longitudinal and cross drainage facilities was found to be one of the major factors.

Material property investigation by laboratory test indicate that subgrade and sub-base materials are with finer grain size, weak CBR strength and high PI value the required value specified by ERA standard, while gradation analysis for base material shows that it is coarser compared with the standard. Bitumen content determination revealed that the asphalt concrete used were with less bitumen content than specified content by standard. From these results it can be generalized that materials used during construction were with weak engineering properties which can be listed as a major cause of failure.Longitudinal and cross drainage facility observation during condition survey has proved that drainage was one cause for distresses to occur and expand to hinder pavement performance.Traffic load analysis has proved that the existing cumulative equivalent standard axle load were much greater than the design cumulative equivalent standard axle load, and the were also concluded to be one of the major causes of distress. Investigation on the impact of distressed pavement indicates that travel speed of vehicles is highly influenced by distress.From all investigation it is understood that the existing maintenance condition is poor. Due to these minor potholes that can be easily maintained and drainage condition that can be managed easily were observed to result in low to high alligator crack and total asphalt surface failure.Therefore, in order to improve the quality of existing pavement urgent maintenance and reconstruction for section with totally failed asphalt surface at $55 \mathrm{~km}-65 \mathrm{~km}$ shall be done considering future traffic and the importance of the existing pavement road for the community.

\section{REFERENCE}

[1]Ahmed,2008.PavementDistressesStudy:IdentificationandMaintenance(casestudy),M.Sc.thes

is, University ofSudan,2008. (Accessed on $25^{\text {th }}$ june 2019)

[2] AASHTO, 1986. AASHTO Guide for Design of Pavement Structures. Standard

Specification for Transportation Materials and Methods of Sampling and Testing. " Part II,

14th Edition, Washington D.C.

[3]AASHTO, 2000. AASHTO specification guide for materials, American Association of State Highway and Transportation Officials, Washington D.C 2000.

[4] Andriejauskas. T, Vorobjovas. V. andMielonas. V. 2014. Evaluation of Skid Resistance

Characteristics and Measurement Methods. 9 International Conference of Environmental

Engineering. Enviro. 2014

[5] Caltrans, (2011). "Flexible Pavement Rehabilitation Manual”, California Department of

Transportation, Sacramento, CA,June, 2001. 
[6] Depaire, B., Wets, G., Vanhoof, K. 2008. Traffic Accident Segmentation By Means Of Latent Class Clustering. Accident Analysis and Prevention 40(4): 1257-1266.

[7] ERA (2013), Ethiopian roads authority site investigation manual, www.era.gov.et Ethiopian roads authority (2006). Road sector development phase II in support of RSDPII supplement, online. Available at projects.worldbank.org/p099480/road-sector-(accessed on 23rd December 2019)

[8] Ethiopian Roads Authority.(2013) Pavement Rehabilitation And Asphalt Overlay Design Manual

[9] F.N. Finn and J. A. Epps (1980). 'Guidelines For Flexible Pavement Failure Investigations" engineering, economy and energy consideration in design, construction and materials. Research report 2-9-74-214-14. Texas transport institute, The Texas A\&M university system college station, Texas 77843. (Accessed on 9th july 2091)

[10] Feng Hand Dar.H,( 2009). Effects of surface preparation, thickness, and material on asphalt pavement overlay transverse crack propagation, NRC Research Press, Can. J. Civ. Eng. Vol. 36. P 1411.

[11] FHWA (2006), Pavement Distress Identification Manual for the NPS Road Inventory Program Cycle 4, 2006-2009, online, available at docplayer.net/38333950/html. (accessed on 3rdjan 2019) [12] H. R. Al-Masaeid. 1997, "Impact of pavement condition on rural road accidents." Canadian Journal of Civil Engineering, Vol. 24, No. 4, pp. 523-531, 1997.

[13] H. Zeng, M.D. Fontaine and B.L. Smith. "Estimation of the Safety Effect of Pavement Condition on Rural, Two-Lane Highways." Transportation Research Record: Journal of the Transportation Research Board, 2435:45-52, 2014.

[14] I.A. Haj-Ismail. 1989 "The Effect of Roadway Surface Condition on Traffic Speed During Day and Night Operations." PhD Thesis, Texas A\&M University, 1989.

Ibrahim worku,(2011). Road Sector Development and Economic Growth in Ethiopia, Ethiopia development research institute working paper $004 \mathrm{~W}$

[15] J. Ben-Edigbe, and N.Ferguson. "Extent of capacity loss resulting from pavement distress. Proceedings of the Institution of Civil Engineers: Transport 158 Issue TR1. pp. 27-32, 2005. Jamaasalih, et al, (2016). Investigating the road maintenance performance in developing country, World Academy of Science, Engineering and Technology International Journal of Civil and Environmental Engineering Vol:10, No:4, 2016Paper 